Author Accepted Version. Final version published as: Rice, J. M., Temple, J. B., \& McDonald, P. F. (2017). Private and public consumption across generations in Australia. Australasian Journal on Ageing, 36(4), 279-285.

\title{
Private and Public Consumption across Generations in Australia
}

\begin{abstract}
\end{abstract}
Objective: To investigate intergenerational equity in consumption using the Australian National Transfer Accounts (NTA).

Methods: Australian NTA estimates of consumption were used to investigate disparities in consumption between people of different ages and generations in Australia between 1981-82 and 2009-10.

Results: There is a clear patterning of consumption by age, with the distribution by age of consumption funded by the private sector being very different to that of consumption funded by the public sector. Australians have achieved notable equality in total consumption among people between the ages of 20 and 75 years. Substantial disparities exist, however, between different generations, with earlier generations experiencing lower levels of total consumption in real terms at particular ages than later generations. Conclusion: An accurate picture of intergenerational equity in consumption requires consideration of both cohorts and cross sections, as well as consumption funded by both the public and the private sectors.

Key words: Australia, consumption, life cycle, private sector, public sector. 


\section{Impact Statement}

This investigation of consumption has implications for debates about the intergenerational equity of policy settings in Australia's ageing population. It sounds warnings for future research concerning: (1) the importance of distinguishing 'crosssectional' and 'cohort' perspectives on consumption and intergenerational equity; and (2) the importance of consumption funded by the public sector. 


\section{Private and Public Consumption across Generations in Australia}

\section{Introduction}

In the context of population ageing, all societies face challenges balancing the needs and wants of people of different ages and generations. One of the challenges faced by policymakers is to manage the intergenerational equity of policy settings as the age distribution of the population shifts beneath them. This, indeed, is stated explicitly in the Australian government's first Intergenerational Report [1].

In a recent issue of $A J A$, Kendig, O'Loughlin, Hussain, and Cannon present new evidence on the attitudes of Australians towards intergenerational equity [2]. They find that a majority of Australians think that older people are getting less than their fair share of government benefits. Most would say that lifelong opportunities have been better for Baby Boomers than for older people who have already retired, while very substantial numbers would also say that Baby Boomers have enjoyed an advantage in lifelong opportunities over younger people.

Intergenerational equity can be assessed along a range of dimensions. For example, it can relate to the equity of the transfers that flow from one generation to another, the distribution of wealth between generations, or the material standards of living experienced by different generations. This article will focus on the last of these dimensions. Specifically, using information from the Australian National Transfer Accounts (NTA), this article will investigate the levels of consumption experienced by 
people of different ages and generations in Australia between 1981-82 and 2009-10, in order to investigate intergenerational equity in material living standards.

\section{Methods}

Material standards of living

Often, material standards of living are studied through the lens of income. Yet, consumption is a more direct and, arguably, a better measure of material living standards [3-6]. Consumption is one of the most important factors determining the welfare of an individual [7-10]. When examining material living standards, the time period over which it is assessed is critical $[3,11]$. Herein material living standards are investigated through the lens of consumption experienced over the course of a year and over the course of a lifetime.

This requires the adoption of two different temporal perspectives on consumption and intergenerational equity. The first $-\mathrm{a}$ 'cross-sectional' perspective - focuses on consumption at a particular point in time (a particular year) and how this consumption varies between people of different ages. The second - a 'cohort' perspective - focuses on consumption over a lifetime and how this consumption varies between people of different generations.

Australian National Transfer Accounts 
Estimates of consumption from the Australian NTA are used to investigate disparities in consumption between people of different ages and generations in Australia between 1981-82 and 2009-10. In order to derive these estimates, macro-level or aggregate amounts of consumption from the Australian System of National Accounts and other information sources are allocated to individuals using a wide array of information sources, including many surveys conducted by the Australian Bureau of Statistics, in conjunction with methods developed by the global NTA project [12]. A total of 12 categories of consumption are delineated on the basis of the type of good or service consumed (education, health, housing, child care, residential aged care, or other) and the funding source (private or public). An overview of the theoretical and mathematical basis of the NTA system, as well as detailed descriptions of methods and data sources, are available elsewhere, including in this issue of $A J A[12-15]$.

Estimates for all years have been converted into 2009-10 dollars per year. Changes are thus presented in real or constant dollar terms.

\section{Results}

\section{Cross-sectional results}

Figure 1 presents per capita age profiles for total consumption, by single years of age, for six time points between 1981-82 and 2009-10. Within these age profiles, four life cycle stages of consumption can be distinguished.

\section{[FIGURE 1]}


The first life cycle stage extends from newborns to people around 20 years of age. In this life cycle stage, total consumption increases with age. The second life cycle stage extends from people around 20 years of age to those around 60. In this life cycle stage, total consumption largely plateaus, varying little with increases in age. The third life cycle stage extends from people around 60 years of age to those around 75 . In this life cycle stage, total consumption again largely plateaus, although at a level slightly higher than in the second life cycle stage. The fourth life cycle stage extends from people around 75 years of age to those of older ages. In this life cycle stage, total consumption rises once again.

The long plateaus in the second and third life cycle stages indicate that Australians have achieved notable equality in total consumption among people between the ages of 20 and 75 years.

Figure 1 also demonstrates that the shape of the per capita age profile for total consumption changed little over the 28 years between $1981-82$ and 2009-10. This age profile has, however, steadily shifted upwards as, across all ages, levels of total consumption have increased in real terms. All ages have benefitted from economic and consumption growth over time.

Table 1 presents, for selected age groups in 1981-82 and 2009-10, estimates of per capita public, private, and total consumption, as well as estimates for the 12 categories of consumption that make up these other totals. There is a clear patterning of these 
consumption categories by age. The broad descriptions provided in the following paragraphs are based on the information for 2009-10.

\section{[TABLE 1]}

Not surprisingly, the consumption of education is highest among younger people and the consumption of health is highest among older people. The consumption of health funded by the public sector generally rises with age, with increases among older people being particularly large. The consumption is health funded by the private sector also rises with age, except that it is lower for people aged 75 years or older than for those aged 60 to 74. Overall, public consumption of health is more substantial than private consumption of health for all age groups. The ratio of private to public health consumption for those aged 19 or younger is roughly similar to that for those aged 75 or older.

While public consumption of housing is small (less than $\$ 170$ for all age groups), private consumption of housing is one of the most substantial categories of consumption. Private housing consumption tends to rise with age. It should be noted that a household's private housing consumption is allocated to members of that household using an equivalence scale. Because older people tend to live in smaller households than others, their private housing consumption will tend to be higher than that of others even if all concerned are living in houses of equal value.

Consumption of residential aged care, both public and private, is almost exclusively experienced by the oldest age group, while consumption of child care is exclusively 
experienced by the youngest. Public consumption of residential aged care is over two times higher than private consumption.

Other public consumption (including consumption of goods and services in areas such as defence, public order and safety, recreation, fuel and energy, agriculture, forestry, transport, and communications) is one of the most substantial categories of consumption. In the NTA system, other public consumption is allocated equally to all individuals, which results in a flat per capita age profile with no patterning by age. The most substantial category of consumption is other private consumption (including consumption of goods and services such as food, beverages, tobacco, clothing, footwear, electricity, gas, furnishings, household equipment, transport, communications, and recreation). Other private consumption roughly doubles from those aged 19 years or younger to those aged 20 to 74, but falls precipitously for those aged 75 or older.

The estimates for change between 1981-82 and 2009-10 reported in the lower third of Table 1 indicate that, across all ages, per capita total consumption rose by $\$ 16,895$ in real terms over this time period. Increases in other private consumption accounted for $38 \%$ of this change in total consumption, while increases in private consumption of housing accounted for $21 \%$. Increases in public health consumption were responsible for $12 \%$ of this change, as were increases in other public consumption. Overall, $70 \%$ of this change was due to changes in private consumption.

These results for all ages mask important differences between age groups. Increases in per capita total consumption between $1981-82$ and 2009-10 varied between $\$ 15,009$ 
for those aged 19 years or younger and $\$ 22,449$ for those aged 75 or older. Overall, around half of the increase in total consumption among those aged 19 or younger was due to changes in private consumption, while the other half was due to changes in public consumption. In contrast, changes in private consumption were largely responsible for the increase in total consumption among those aged 20 to 74, while changes in public consumption were largely responsible for the increase in total consumption among those aged 75 or older. Changes in public and private consumption particularly benefitted those aged 75 or older and those aged 20 to 74 , respectively.

For all age groups except those aged 75 years or older, there were substantial increases in other private consumption. Reflecting increases in the value of people's houses, private consumption of housing increased substantially for all age groups but especially for the two older age groups for whom the number of persons per household was lower. Changes in public health consumption were important for those aged 60 years or older, but were less important for those aged 59 or younger. Increases in public and private consumption of education made up 36\% of the consumption increase for those aged 19 or younger, partly reflecting increases in educational participation.

\section{Cohort results}

So far, this article has adopted a 'cross-sectional' perspective on consumption. A 'cohort' perspective is adopted in Figure 2 which presents estimates of per capita total consumption for different generations as they age between 1981-82 and 2009-10. Birth cohorts, defined by year of birth, are grouped into generations. The groupings of birth cohorts are as follows (with the associated generations in parentheses): 1926-1945 (the 
Traditionalists), 1946-1965 (the Baby Boomers), 1966-1985 (Generation X), and 1986-2005 (the Millennials). These groupings and generational names are derived from a range of sources $[16,17]$. In Figure 2, four selected birth cohorts are presented per generation.

\section{[FIGURE 2]}

Figure 2 also includes lines for the 1981-82 and 2009-10 cross sections. These lines are identical to those for 1981-82 and 2009-10 in Figure 1. As generations age between 1981-82 and 2009-10, they move from somewhere on the line for the 1981-82 cross section to somewhere on the line for the $2009-10$ cross section.

Looking at the trajectories experienced by the different generations as they age, one thing is clear: these trajectories, with very few exceptions, are trajectories of continuously rising total consumption in real terms. For all generations, total consumption is higher in 2009-10 than in 1981-82 and, with very few exceptions, each increase in age has been associated with an increase in total consumption.

These trajectories of rising total consumption are very different to the long plateaus in total consumption between the ages of 20 and 74 years indicated by the lines for the 1981-82 and 2009-10 cross sections. For example, while in 2009-10 the difference in total consumption between 26-year-olds and 54-year-olds was $\$ 2,754$, Baby Boomers born in 1955 (the solid, dark grey line with diamonds in Figure 2) experienced a rise in total consumption of 6.7 times that amount as they aged from 26 to 54 years. To take another example, in 2009-10 the difference in total consumption between 46-year-olds 
and 74-year-olds was $\$ 4,942$. In contrast, Traditionalists born in 1935 (the solid, black line with squares) experienced an increase in total consumption of 3.6 times that amount as they aged from 46 to 74 years.

The trajectories experienced by the different generations as they age reveal substantial disparities in total consumption between the generations, with generations born in earlier years experiencing lower levels of total consumption in real terms at particular ages than those born in later years. This reflects the fact that all generations have benefitted from economic and consumption growth over time.

One way to illustrate these disparities is to look at how long different generations took to achieve a level of total consumption of $\$ 30,000$. At one extreme, Traditionalists born in 1935 achieved this level of total consumption when they were roughly 50 years of age. At the other extreme, Millennials born in 1995 (the solid, light grey line with circles) had achieved this level of total consumption by the time they were around 10 .

Another way to illustrate these disparities is to look at the level of total consumption experienced by the generations at particular ages. For example, when Traditionalists born in 1935 were 53 years of age, their total consumption was about $\$ 30,315$. In contrast, when Baby Boomers born in 1955 were a similar age, their total consumption was about $\$ 43,126$ (that is, $\$ 12,811$ higher). Similarly, Baby Boomers born in 1955 had a total consumption of $\$ 26,588$ when they were 33 years of age, whereas members of Generation $\mathrm{X}$ born in 1975 had a total consumption of $\$ 39,589$ (that is, $\$ 13,001$ higher) when they were a similar age. Members of Generation X born in 1975 had a total consumption of $\$ 24,970$ when they were 13 years of age, whereas Millennials born in 
1995 had a total consumption of $\$ 38,044$ (that is, $\$ 13,074$ higher) when they were a similar age. With very few exceptions, later generations experienced higher levels of total consumption at particular ages than earlier generations.

The contributions made by the 12 categories of consumption to the three differences mentioned in the previous paragraph are explored in Figure 3. The first column indicates that Millennials born in 1995 experienced \$13,074 more total consumption than members of Generation X born in 1975 when 13-14 years of age largely because the Millennials experienced higher levels of public consumption of education, other public consumption, private consumption of housing, and other private consumption. The second and third columns indicate that differences between the associated generations are largely due to differences in levels of other public consumption, private housing consumption, and other private consumption. Overall, differences in private consumption between generations accounted for $52 \%$ of the difference in the first column, $83 \%$ of the difference in the second column, and $81 \%$ of the difference in the third column.

\section{[FIGURE 3]}

\section{Discussion}

The Australian NTA estimates presented herein do not provide a completed cohort view of total consumption over a lifetime. Nevertheless, these estimates suggest that, all else held equal, of the Traditionalists, the Baby Boomers, Generation X, and the Millennials, those generations born in earlier years will experience substantially lower levels of total 
consumption in real terms over their lifetimes than those generations born in later years. The new attitudinal evidence presented by Kendig, O'Loughlin, Hussain, and Cannon points to a belief that Baby Boomers have enjoyed better lifelong opportunities than earlier and later generations [2]. The Australian NTA estimates suggest that Baby Boomers have experienced higher levels of consumption than earlier generations at the same age, but lower levels of consumption than later generations at the same age. This reflects the fact that all generations have benefitted from economic and consumption growth over time.

The results presented in this article sound a number of warnings concerning the study of consumption and intergenerational equity. One of these is that great caution must be used if differences between people of different ages at a particular point in time are utilised to infer something about the trajectories experienced by people as they age. Cross-sectionally, consumption differences between people of different ages at a particular point in time can be relatively small. But this can be consistent with, from a cohort perspective, the consumption trajectories experienced by people as they age being trajectories, not of relatively small differences from one age to the next, but of substantial rises.

Another warning relates to the importance of public consumption. As evident from Table 1, the distribution by age of private consumption is very different to that of public consumption. In 2009-10, for example, private consumption was lowest among younger people and older people. Public consumption, however, was highest among these age groups. Many studies of consumption focus on private consumption alone and ignore public consumption $[4,5,7,18]$, but this focus is likely to yield an inaccurate 
picture of total consumption. One of the valuable qualities of the Australian NTA is its inclusion of public consumption as an integral part of total consumption.

The consumption estimates from the Australian NTA are subject to a number of qualifications. They do not take into account the different needs of people of different ages. More specifically, they do not take account of their consumption relative to their underlying needs. For example, children typically need less other private consumption than adults. Older adults typically need more public health consumption than younger adults, as well as more residential aged care consumption. These estimates also do not take into account the full economies of scale in consumption $[3,6,11]$, which are of more benefit to people who live in larger households, such as many children, but which are of less benefit to people who live in smaller households, such as many older people. Different needs and economies of scale are likely to imply that the material living standards of children are higher than suggested in this article, while the material living standards of older people are lower than suggested.

These estimates can also be affected by changes in the composition of people of different ages, which can occur through processes such as selective mortality and migration. These compositional changes have not been modelled in this article.

These estimates also do not illuminate how intergenerational equity in consumption might be affected by factors other than age that influence consumption, such as educational level, occupation, gender, or ethnicity. Other factors such as these will be investigated in future Australian NTA research. 
This article has investigated intergenerational equity in the material standards of living experienced by people of different ages and generations through the lens of consumption. Intergenerational equity can be assessed along a range of other dimensions, however, such as the transfers that flow from one generation to another or the distribution of wealth between generations. Some authors have noted crosssectional inequalities in home ownership by age as a reason to believe wealth inequalities will be exacerbated across generations [9, 19]. Indeed, analyses of Australian NTA estimates demonstrate that a significant proportion of the increase in wealth that occurred between 2003-04 and 2009-10 accrued to those aged 55 to 64 years [20]. However, most of this increase in wealth was held in the family home, which is a relatively illiquid asset made even more so by existing eligibility requirements for the Age Pension. Nevertheless, there are other reasons to believe later generations of older Australians may not fare as well as the Baby Boomers [21]. Other transfer-based and wealth-based dimensions of intergenerational equity will be investigated in future Australian NTA research.

\section{References}

1. Commonwealth of Australia. Intergenerational Report 2002-03. Canberra: Commonwealth of Australia, 2002.

2. Kendig $\mathrm{H}$, O’Loughlin $\mathrm{K}$, Hussain $\mathrm{R}$, Cannon L. Attitudes towards Intergenerational Equity: Preliminary Australian Evidence. Australasian Journal on Ageing. 2017; 36(2): 107-111.

3. Atkinson AB. The Economics of Inequality. 2nd edn. Oxford: Clarendon Press, 1983. 
4. Barrett GF, Crossley TF, Worswick C. Consumption and Income Inequality in Australia. Economic Record. 2000; 76(233): 116-138.

5. Barrett GF, Crossley TF, Worswick C. Demographic Trends and Consumption Inequality in Australia between 1975 and 1993. Review of Income and Wealth. 2000; 46(4): 437-456.

6. Travers P, Richardson S. Living Decently: Material Well-Being in Australia. Melbourne: Oxford University Press, 1993.

7. Attanasio OP. Consumption. In: Taylor JB, Woodford M (eds). Handbook of Macroeconomics: Volume 1B. Amsterdam: North-Holland Elsevier, 1999; $741-812$.

8. Australian Bureau of Statistics. Australian System of National Accounts: Concepts, Sources and Methods. Australia: 2015. Canberra: Australian Bureau of Statistics, 2016. ABS Catalogue No. 5216.0.

9. Daley J, Wood D, Weidmann B, Harrison C. The Wealth of Generations. Melbourne: Grattan Institute, 2014. Report No. 2014-13.

10. Tung A-C. Consumption over the Lifecycle: An International Comparison. In: Lee R, Mason A (eds). Population Aging and the Generational Economy: A Global Perspective. Cheltenham, Northampton, and Ottawa: Edward Elgar and the International Development Research Centre, 2011; 136-160.

11. Harding A. Lifetime Income Distribution and Redistribution: Applications of a Microsimulation Model. Amsterdam: North-Holland, 1993.

12. United Nations Department of Economic and Social Affairs. National Transfer Accounts Manual: Measuring and Analysing the Generational Economy. New York: United Nations, 2013. 
13. Lee R, Mason A (eds). Population Aging and the Generational Economy: A Global Perspective. Cheltenham, Northampton, and Ottawa: Edward Elgar and the International Development Research Centre, 2011.

14. Rice JM, Temple J, McDonald P. National Transfer Accounts for Australia: 2003-04 and 2009-10 Detailed Results: ARC Centre of Excellence in Population Ageing Research and Crawford School of Public Policy, Australian National University, 2014.

15. The Authors. Ageing and the Economic Lifecycle: The National Transfer Accounts Approach. Australasian Journal on Ageing. 2017; this issue.

16. Australian Bureau of Statistics. A Picture of the Nation: The Statistician's Report on the 2006 Census. Canberra: Australian Bureau of Statistics, 2009. ABS Catalogue No. 2070.0.

17. Lancaster LC, Stillman D. When Generations Collide: Who They Are. Why They Clash. How to Solve the Generational Puzzle at Work. New York: Harper Collins Publishers, 2002.

18. Browning M, Crossley TF. The Life-Cycle Model of Consumption and Saving. Journal of Economic Perspectives. 2001; 15(3): 3-22.

19. Eslake S. No Place Like Home: The Impact of Declining Home Ownership on Retirement. Melbourne: Australian Institute of Superannuation Trustees, 2017.

20. The Authors. 2017. Net Assets Available at Age of Death in Australia: An Extension of the National Transfer Accounts Methodology. Population Review. Forthcoming.

21. Kendig H. Directions and Choices on Ageing for the Future. In: O'Loughlin K, Browning $\mathrm{C}$, Kendig $\mathrm{H}$ (eds). Ageing in Australia: Challenges and Opportunities. New York: Springer, 2017; 263-279. 


\section{University Library}

\section{- M M I N E R VA A gateway to Melbourne's research publications}

Minerva Access is the Institutional Repository of The University of Melbourne

Author/s:

Rice, JM;Temple, JB;McDonald, PF

Title:

Private and public consumption across generations in Australia

Date:

2017-12-01

Citation:

Rice, J. M., Temple, J. B. \& McDonald, P. F. (2017). Private and public consumption across generations in Australia. AUSTRALASIAN JOURNAL ON AGEING, 36 (4), pp.279-285. https://doi.org/10.1111/ajag. 12489.

Persistent Link:

http://hdl.handle.net/11343/253838 